\title{
The effects of periosteum removal on the osteocytes in mouse calvaria
}

\author{
Songtao $\mathrm{Wu}^{1 *}$, Zayar Lin ${ }^{1}$, Akira Yamaguchi ${ }^{2}$ and Shohei Kasugai ${ }^{1}$ \\ ${ }^{1}$ Department of Oral Implantology and Regenerative Dental Medicine, Graduate School of Medical and Dental Sciences, Tokyo Medical and Dental University, \\ Tokyo, Japan \\ ${ }^{2}$ Department of Oral Pathology, Graduate School of Medical and Dental Sciences, Tokyo Medical and Dental University, Japan
}

\begin{abstract}
Objectives: To investigate the early influence of periosteum removal on osteocytes in mouse calvaria.

Material and methods: Fifteen C57BL/6 male mice were used in this study. Under anesthesia, a $2 \mathrm{X} 3 \mathrm{~mm}$ rectangular shape periosteum, $2 \mathrm{~mm}$ behind the coronal suture and $1 \mathrm{~mm}$ beside the sagittal suture, was surgically removed from the left side of calvaria whereas the right side was intact as control. Five mice were sacrificed at 1 day, 3 days and 7 days after the operation and the calvaria together with the surrounding tissues were histologically examined.
\end{abstract}

Results: At 3 days and 7 days, the number of empty lacunae significantly increased at the periosteum stripped side compared to the intact control side. The empty lacunae were mainly restricted to the outer half of the calvaria under the periosteum stripped area. Sclerostin distribution in lacunae and canaliculi also dramatically decreased at the periosteum stripped side at all the time points.

Conclusion: Periosteum removal would induce early apoptosis of the osteocytes in the outer layer of the bone and decrease sclerostin within this area.

\section{Introduction}

Periosteum, the stiff envelope bounds the skeleton, plays an essential role in offering protection and nutrition to the cortical bone [1]. Furthermore, periosteum also severs as a reservoir of progenitor cells and preserves a remarkable bone regeneration capacity, which is crucial for both prenatal bone development and postnatal fracture healing [2]. For immature skeletal system, periosteum-derived ossification makes long bones grow radially [3] and in fracture healing process, periosteum is also inevitable [4]. The formation of cartilage and bone within the callus owes largely to the mesenchymal progenitor cell from the periosteum [5]. When the periosteum is irritated by trauma, infection, neoplasia, or sometimes surgical procedure, new bone would be rapidly formed, which is favorable or unfavorable [6-9]. A previous study showed that the elevation of periosteum can induce new bone formation underneath [10]. In spite of the importance of periosteum, in some surgical circumstances, it has to be completely removed from the bone surface, such as in proper open reduction and in plate applications for treating bone fractures [11], and surgical removal of soft tissue sarcomas (STS) to ensure the adequate surgical margins [12]. In dental implant surgeries, clinicians often apply tension releasing incisions, cutting the periosteum at the base of the muco-periosteal flap to complete a primary closure, especially in ridge expansion procedures [13]. This incision into the periosteal layer leaves a hole, resulting in direct contact of the mucosa to the cortical bone, which can be considered as another kind of the periosteum stripping.

The apoptosis of osteocyte is another highlighted topic, which is already known to be a result of many physiological or pathological changes, such as rapid modeling process [14], age-associated oxidative stress [15], estrogen deficiency [16], overwhelming of glucocorticoid [17]. Also from a mechanical view, unloading of bone which weakens the canaliculiar fluid shear stress will result in osteocyte apoptosis [18]. Conversely, excessive loading which produces microdamage disrupting the canaliculiar system integrity also leads to osteocyte apoptosis [19].

Although the studies concerning periosteum stripping or osteocyte apoptosis have been often reported respectively, the reaction of osteocytes to the periosteum stripping has not been clarified yet. In this study, we histologically examined the effects of periosteum removal on the osteocytes in mouse calvaria.

\section{Materials and methods}

\section{Animal models}

Fifteen male C57BL/6 mice of 12 weeks old, weighing 25-30g, were used in this study. All the experimental procedures had been approved by the Animal Experiment Committee at Tokyo Medical and Dental University. (Approval number: 0140174A).

Correspondence to: Songtao $\mathrm{Wu}$, Department of Oral Implantology and Regenerative Dental Medicine, Graduate School of Medical and Dental Sciences, Tokyo Medical and Dental University, Tokyo113-8549, Japan, Tel: +8135803 4664; E-mail: wstcbh@hotmail.com; songirm@tmd.ac.jp

Received: September 27, 2015; Accepted: October 20, 2015; Published: October 26,2015 


\section{Surgical procedure}

General anesthesia was performed by an intraperitoneal injection of a combination of ketamine and xylazine $(75 \mathrm{mg}$ and $0.5 \mathrm{mg}$ per $\mathrm{kg}$ body weight, respectively). The hair of calvarial zone was shaved and the skin over the skull was cleaned with $70 \%$ ethanol. Incision of $20 \mathrm{~mm}$ length was made in the central line of head and partial thickness flap was raised. A $2 \times 3 \mathrm{~mm}$ rectangular $(2 \mathrm{~mm}$ behind the coronal suture and $1 \mathrm{~mm}$ beside the sagittal suture) area was marked with ink on left side of calvarial periosteum (Figure 1A). Then, the stripping was performed with scalpel and dental excavator to remove the periosteum completely (Figure 1B and 1C). The right side of calvaria was intact as control. Finally the surgical area was closed with suturing.

Five mice were sacrificed for each time point at 1,3 and 7 days after the operation. Following the anesthesia mentioned above, a perfusion fixation with $4 \%$ paraformaldehyde was performed to secure the bone tissue. Then, the whole calvarial bone together with the skin was harvested and fixed in the $4 \%$ paraformaldehyde.

\section{Procedure for histological analysis}

After fixation in $4 \%$ paraformaldehyde at $4^{\circ} \mathrm{C}$ for 2 days and washing in phosphate buffered saline (PBS) at $4^{\circ} \mathrm{C}$ for 1 days, samples were decalcified in $20 \%$ ethylenediaminetetraacetic acid (EDTA) at $4^{\circ} \mathrm{C}$ for 14 days and embedded in paraffin. Serial sections of $4 \mu \mathrm{m}$ thickness were prepared and subjected to hematoxylin and eosin (HE) staining and immunohistochemical (IHC) staining. Images of stained specimens were acquired with an upright microscope (AxioSkop2, Carl Zeiss, Oberkochen, Germany).

\section{Immunohistochemical (IHC) staining}

Immunohistochemistry analysis of markers for sclerostin was carried out in the paraffin embedded sections. Briefly, deparaffinized and hydrated sections were incubated with $0.1 \%$ trypsin solution (Difco ${ }^{\mathrm{TM}}$ Trypsin 250, BD Biosciences) for 20 minutes in water bath at $37^{\circ} \mathrm{C}$. After cooling, the sections were rinsed with Tris-buffered solution (50mM Tris, $150 \mathrm{mM} \mathrm{NaCl}$ and $0.05 \%$ Tween 20, TBST) and incubated with $3 \%$ hydrogen peroxide in methanol for 30 minutes at room temperature to remove the internal peroxidase. After rinsing the sections with TBST, sections were incubated with the primary antibody
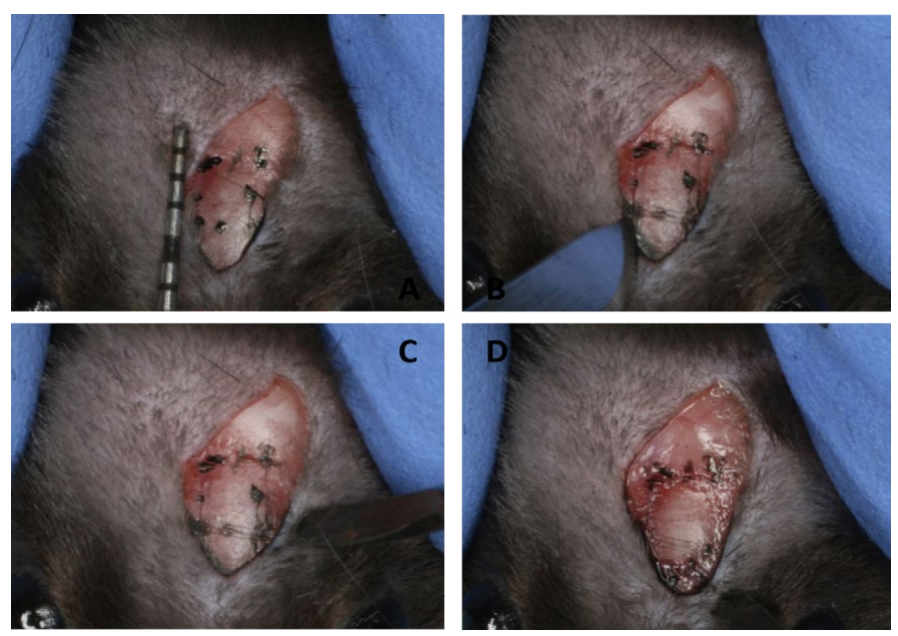

Figure 1. A: A $2 \times 3 \mathrm{~mm}$ rectangular $(2 \mathrm{~mm}$ behind the coronal suture and $1 \mathrm{~mm}$ beside the sagittal suture) area was marked with ink on left side of calvarial periosteum. B, C: Periosteum within the area was cut by scalpel and removed by dental excavator. D: The bone surface after periosteum stripping. (goat-anti-mouse sclerostin 1:200, R\&D Systems, Minneapolis, MN) diluted in TBST overnight at $4^{\circ} \mathrm{C}$ in a humidifying chamber. After washes with TBST, secondary antibody (Histofine RR Simple Stain ${ }^{\mathrm{TM}}$ Mouse MAX-PO(G), Nichirei, Tokyo, Japan) was applied and incubated with the sections for 1 hour at room temperature. Sections were developed with 3,3N-diaminobenzidine tertrahydrochloride (DAB) for 2.5 minutes and, after washing with tap water, counterstained with $1 \%$ methyl green for 20 minutes. Slides were mounted using permount mounting media (Fisher Scientifics). Images of stained specimens were acquired in the same way as HE staining.

\section{Histomorphometry analysis}

For histomorphometric analysis of HE stain slides, high resolution digital images (at 10 times magnification) were acquired on the left side of calvaria within bone area $1 \mathrm{~mm}$ away from the sagittal suture, and the same area of the control side. For the images of both sides, the number of empty lacunae and total lacunae was counted using the enlarged images. In the same area of HE stain slide, the images of sclerostin immunohistochemical stain slides were also obtained.

\section{Statistical analysis}

Statistical analyses were performed with standard Student's t-tests for comparisons between different sides of within the same time point. The one-way analysis of variance (ANOVA) was employed for longitudinal comparisons between different time points of the same side.

\section{Results}

\section{Histological findings}

In the HE stain slides, the periosteum stripping side showed slightly increased number of empty lacunae than control side at day 1. The number of empty lacunae increased significantly on periosteum stripping side than the control side at day 3 and 7 . Interestingly, the number of empty lacunae also increased at day 7 in control side (Figures 2 and 3). Notably, almost all the empty lacunae were found in the outer half of the calvaria, whereas the inner half layer was less affected.

\section{Immunohistochemical (IHC) stain}

In all 3 time points, the periosteum removal sides showed less staining for sclerostin whereas the control sides showed more sclerostin distribution among osteocytes. Also in control side, a clear network of canaliculi radius, which was positively stained, spread out from the lacunae in the middle or inner layer of the bone could be often observed. However in the periosteum removed side, even in the 1day group, the canaliculi existing sclerostin were seldom observed around the lacunae (Figure 4).

\section{Discussion}

The empty lacunae are the most simple and direct indication of osteocyte apoptosis among several histological detection methods in vivo [20]. This phenomenon has been initially reported as the evidence of osteocytes loss in the aged patients about half century ago [21]. Although many factors can promote osteocyte apoptosis, in the present study, the periosteum stripping seems to be the reason that largely increases the number of empty lacunae at day 3 and day 7. This may be considered as the result of cutting off the main blood supply in the area. As reported previously, the stripping of periosteum significantly decreases the perfusion up to $20 \%$ of the whole length of tibia [11]. While for an irregular shape bone like mandible, as Saka B 


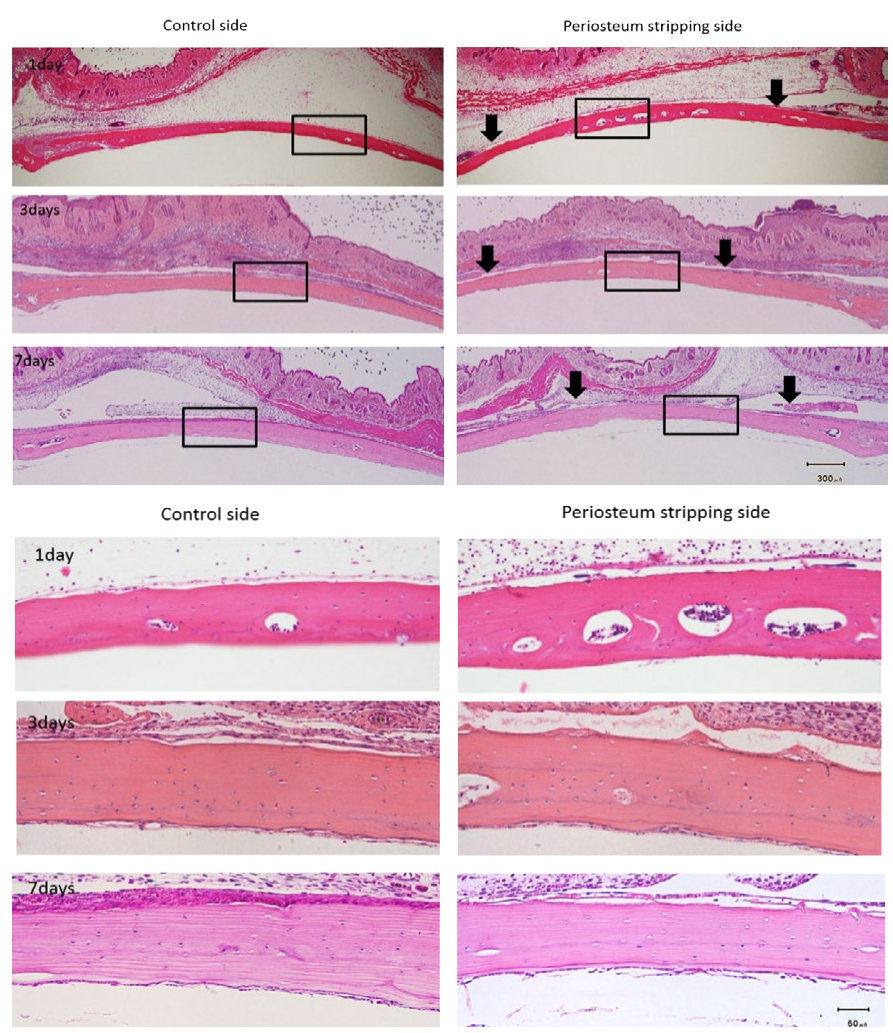

Figure 2. The number of empty lacunae increased significantly on periosteum stripping side than the control side at day 3 and 7 and almost all the empty lacunae were in the outer half of the calvaria. (Above: black arrows show the cutting edges of periosteum, bar as $300 \mu \mathrm{m}$. Below: high magnificent of rectangular area in picture A, bar as $50 \mu \mathrm{m}$ ).

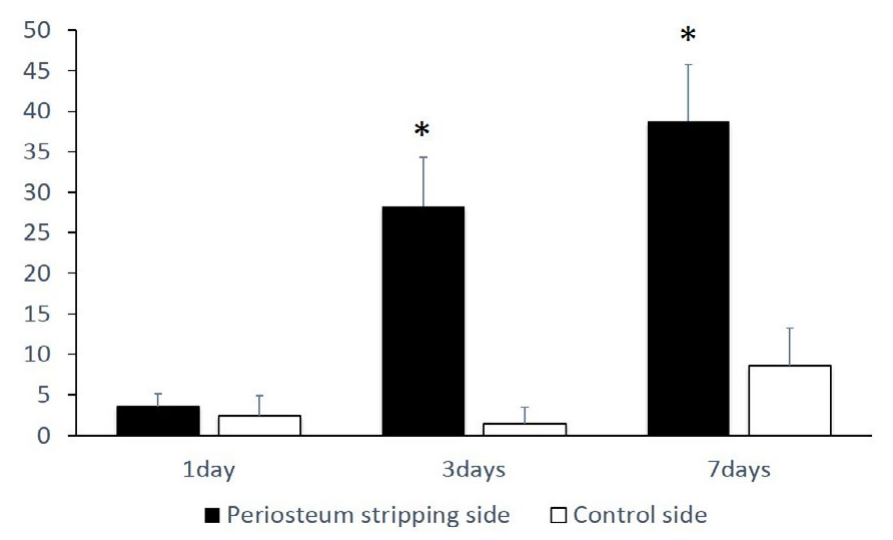

Figure 3. A significant increase in empty lacunae number on periosteum stripping side, comparing to the control side at day 3 and $7 .\left({ }^{*}=\mathrm{p}<0.05\right)$.

et al. reported, periosteal blood supply predominated in the body of the mandible [22]. Calvarium also has the similar structure of thick cortex with less marrow as the edentulous mandible. Another evidence to support this speculation is that the empty lacunae are mainly seen in the outer layer of the cavlaria, where can be taken as the periosteum nutritious domain as illustrated by the study of Pazzaglia et al. [23].

From the result of this study, the death signal may be released in the first day after the stripping, but the autophagy of osteocyte seems takes sometime which leads to the similar empty lacunae amount and rates on both sides at day 1 . But soon the process ends itself and leaves the empty lacunae under the periosteum stripped side on the 3rd day. Interestingly, this death area did not enlarge to the day 7 , indicating that it was determined at the first place when the periosteum was cut off.

This early death of osteocyte may lead to an osteoclastic resorption which could explain the previous finding that the long term bone density and mechanical properties dropped in the extensive circumferential periosteal stripping femur model [12]. Also it can enlighten the reason of high fracture risk after the STS surgical resection from the histological view [24]. For the surgery of oral implant, a tension releasing incision cut into the periosteal layer or placing a membrane and bone substitutes under the muco-periosteal flap may all cause the bone, especially the cortex of mandibular, losing the essential blood supply from periosteum, therefore it may undermine the basal bone where implant will be or already been placed in. Nevertheless, in a pilot study (date not shown), a simple elevation and reposition of periosteum, mimicking an open flap surgery in oral cavity, does not affect the osteocytes.

Sclerostin, the protein product of the SOST gene, acts as a negative regulator of bone formation and recently became a target for the anabolic treatment of osteoporosis [25]. This protein is mainly produced by osteocytes [26] and antagonizes the canonical Wnt signaling pathway to inhibit the osteoblast bone formation [27]. As mentioned previously, periosteum serves as not only a nutrition supply source but also as an important reservoir of osteoblasts. These cells have close interconnections with the osteocytes network via gap junctions [28] and extracellular paracrine signaling pathways [29]. Therefore, the osteoblasts in periosteum could be the most direct targets that osteocyte can aim at with the signals, such as, sclerostin.

Sclerostin is considered as a mechanotransduction key molecule which expression is enhanced by mechanical unloading [30], or suppressed by loading [31]. In the present study, the decreasing of sclerostin around the osteocytes still exist in the inner layer bone of the periosteum stripping side, cannot be explained by the loading theory, since calvaria unlike tibia or femur, is not under a daily body weight loading.

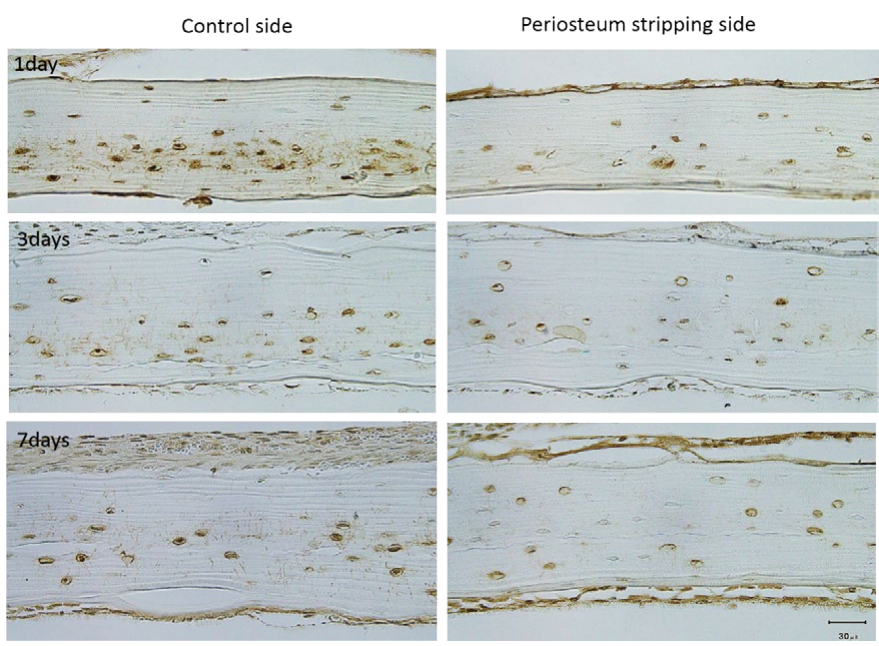

Figure 4. At all 3 time points, the periosteum stripping sides showed less staining for sclerostin than the control sides. A clear network of canaliculi radius spread out from the lacunae in the middle or inside layer of calvaria could be observed, stained with brown color, while seldom canaliculi could be seen on the periosteum stripping sides in all groups. (bar as $30 \mu \mathrm{m}$ ). 
Bone fatigue can induce osteocyte apoptosis which is then followed by the osteoclastic resorption within the region around microcracks [32]. Loss of the periosteum could be a trauma similar to the microcrack inducing osteocyte apoptosis close under it. Therefore, this periosteum stripping would also raise the wave of resorption and remodeling, which requires suppression of sclerostin expression to turn on osteoblast bone formation. This suppression of sclerostin has also been seen in the bone after a dental implant placement [33]. Since lacking of sclerostin may stimulate osteoblast and enhance the bone regeneration process, it would be interesting to observe a long term remolding of the bone with periostuem stripped in the future study.

\section{Conclusion}

Periosteum removal can result in an early apoptosis to the osteocytes in outer layer of skull and a reduction of sclerostin within that area.

\section{Conflict of interest}

The authors do not have any conflict of interest.

\section{References}

1. Lin Z, Fateh A, Salem DM, Intini G (2014) Periosteum: biology and applications in craniofacial bone regeneration. J Dent Res 93: 109-116. [Crossref]

2. Chang H, Knothe Tate ML (2012) Concise review: the periosteum: tapping into a reservoir of clinically useful progenitor cells. Stem Cells Transl Med 1: 480-491. [Crossref]

3. Clarke B (2008) Normal bone anatomy and physiology. Clin J Am Soc Nephrol 3 Suppl 3: S131-139. [Crossref]

4. Bullens PH, Schreuder H, Malefijt MC, Verdonschot N, Buma P (2010) The presence of periosteum is essential for the healing of large diaphyseal segmental bone defects reconstructed with trabecular metal: a study in the femur of goats. J Biomed Mater Res B Appl Biomater 92: 24-31. [Crossref]

5. Colnot C (2009) Skeletal cell fate decisions within periosteum and bone marrow during bone regeneration. J Bone Miner Res 24: 274-282. [Crossref]

6. de Billy B, Gindraux F, Langlais J (2014) Osteotomy and fracture fixation in children and teenagers. Orthop Traumatol Surg Res 100: S139-148. [Crossref]

7. Mehra H, Gupta S, Gupta H, Sinha V, Singh J (2013) Chronic suppurative osteomyelitis of mandible: a case report. Craniomaxillofac Trauma Reconstr 6: 197-200. [Crossref]

8. Mallikarjun K, Kohli A, Kumar A, Tanwar A (2011) Chronic suppurative osteomyelitis of the mandible. J Indian Soc Pedod Prev Dent 29: 176-179. [Crossref]

9. Manjunatha BS, Das N, Sutariya R, Ahmed T (2013) Peripheral osteoma of the body of mandible. BMJ Case Rep 2013. [Crossref]

10. Zakaria O, Madi M, Kasugai S (2012) A novel osteogenesis technique: The expansible guided bone regeneration. J Tissue Eng 3: 2041731412441194. [Crossref]

11. Kowalski MJ, Schemitsch EH, Kregor PJ, Senft D, Swiontkowski MF (1996) Effect of periosteal stripping on cortical bone perfusion: a laser doppler study in sheep. Calcif Tissue Int 59: 24-26. [Crossref]

12. Mercurio AD, Motta T, Green E, Noble G, Hart RT et al. (2012) Effects of extensive circumferential periosteal stripping on the microstructure and mechanical properties of the murine femoral cortex. J Orthop Res 30: 561-568. [Crossref]

13. Greenstein G, Greenstein B, Cavallaro J, Elian N, Tarnow D (2009) Flap advancement: practical techniques to attain tension-free primary closure. $J$ Periodontol 80: 4-15. [Crossref]
14. Noble BS, Stevens H, Loveridge N, Reeve J (1997) Identification of apoptotic changes in osteocytes in normal and pathological human bone. Bone 20: 273-282. [Crossref]

15. Almeida M, Han L, Martin-Millan M, Plotkin LI, Stewart SA, et al. (2007) Skeletal involution by age-associated oxidative stress and its acceleration by loss of sex steroids. J Biol Chem 282: 27285-27297. [Crossref]

16. van Essen HW, Holzmann PJ, Blankenstein MA, Lips P, Bravenboer N (2007) Effect of raloxifene treatment on osteocyte apoptosis in postmenopausal women. Calcif Tissue Int 81: 183-190. [Crossref]

17. Weinstein RS, Manolagas SC (2000) Apoptosis and osteoporosis. Am J Med 108: 153164. [Crossref]

18. Aguirre JI, Plotkin LI, Stewart SA, Weinstein RS, Parfitt AM, et al. (2006) Osteocyte apoptosis is induced by weightlessness in mice and precedes osteoclast recruitment and bone loss. J Bone Miner Res 21: 605-615. [Crossref]

19. Reilly GC, Currey JD (2000) The effects of damage and microcracking on the impact strength of bone. J Biomech 33: 337-343. [Crossref]

20. Jilka RL, Noble B, Weinstein RS (2013) Osteocyte apoptosis. Bone 54: 264-271 [Crossref]

21. Frost HM (1960) In vivo osteocyte death. J Bone Joint Surg Am 42-42A: 138-43. [Crossref]

22. Saka B, Wree A, Henkel KO, Anders L, Gundlach KK (2002) Blood supply of the mandibular cortex: an experimental study in Göttingen minipigs with special reference to the condyle. J Craniomaxillofac Surg 30: 41-45. [Crossref]

23. Pazzaglia UE, Bonaspetti G, Ranchetti F, Bettinsoli P (2008) A model of the intracortical vascular system of long bones and of its organization: an experimental study in rabbit femur and tibia. $J$ Anat 213: 183-193. [Crossref]

24. Blaes AH, Lindgren B, Mulrooney DA, Willson L, Cho LC (2010) Pathologic femur fractures after limb-sparing treatment of soft-tissue sarcomas. J Cancer Surviv 4: 399404. [Crossref]

25. van Dinther M, Zhang J, Weidauer SE, Boschert V, Muth EM, et al. (2013) AntiSclerostin antibody inhibits internalization of Sclerostin and Sclerostin-mediated antagonism of Wnt/LRP6 signaling. PLoS One 8: e62295. [Crossref]

26. Poole KE, van Bezooijen RL, Loveridge N, Hamersma H, Papapoulos SE, et al. (2005) Sclerostin is a delayed secreted product of osteocytes that inhibits bone formation. FASEB J 19: 1842-1844. [Crossref]

27. van Bezooijen RL, Roelen BA, Visser A, van der Wee-Pals L, de Wilt E, et al. (2004) Sclerostin is an osteocyte-expressed negative regulator of bone formation, but not a classical BMP antagonist. J Exp Med 199: 805-814. [Crossref]

28. Marotti G, Ferretti M, Muglia MA, Palumbo C, Palazzini S (1992) A quantitative evaluation of osteoblast-osteocyte relationships on growing endosteal surface of rabbit tibiae. Bone 13: 363-368. [Crossref]

29. Mo C, Romero-Suarez S, Bonewald L, Johnson M, Brotto M (2012) Prostaglandin E2: from clinical applications to its potential role in bone- muscle crosstalk and myogenic differentiation. Recent Pat Biotechnol 6: 223-229. [Crossref]

30. Lin C, Jiang X, Dai Z, Guo X, Weng T, et al. (2009) Sclerostin mediates bone response to mechanical unloading through antagonizing $\mathrm{Wnt} /$ beta-catenin signaling. $J$ Bone Miner Res 24: 1651-1661. [Crossref]

31. Moustafa A, Sugiyama T, Prasad J, Zaman G, Gross T, Lanyon L, et al. (2012) Mechanical loading-related changes in osteocyte sclerostin expression in mice are more closely associated with the subsequent osteogenic response than the peak strains engendered. Osteoporos Int 23: 1225-1234. [Crossref]

32. Verborgt O, Gibson GJ, Schaffler MB (2000) Loss of osteocyte integrity in association with microdamage and bone remodeling after fatigue in vivo. $J$ Bone Miner Res 15: 60-67. [Crossref]

33. Haga M, Nozawa-Inoue K, Li M, Oda K, Yoshie S, et al. (2011) A morphological analysis on the osteocytic lacunar canalicular system in bone surrounding dental implants. Anat Rec (Hoboken) 294: 1074-1082. [Crossref]

Copyright: (C2015 Wu S. This is an open-access article distributed under the terms of the Creative Commons Attribution License, which permits unrestricted use, distribution, and reproduction in any medium, provided the original author and source are credited. 